\title{
A Comparative Evaluation of the Physical and Chemical Characteristics of Composted Tea Tree (Melaleuca alternifolia L.) with Pine Bark Growing Media in Tobacco (Nicotiana tabucum L.) Seedling Production
}

\author{
Johnson Masaka, ${ }^{1}$ Noel Chimwanda, ${ }^{2}$ Ignatius Chagonda, ${ }^{2}$ and Misheck Chandiposha ${ }^{2}$ \\ ${ }^{1}$ Department of Land and Water Resources Management, Midlands State University, Private Bag 9055, Gweru, Zimbabwe \\ ${ }^{2}$ Department of Agronomy, Midlands State University, Private Bag 9055, Gweru, Zimbabwe
}

Correspondence should be addressed to Johnson Masaka; masakaj@msu.ac.zw

Received 13 October 2015; Revised 29 January 2016; Accepted 3 February 2016

Academic Editor: Tibor Janda

Copyright (C) 2016 Johnson Masaka et al. This is an open access article distributed under the Creative Commons Attribution License, which permits unrestricted use, distribution, and reproduction in any medium, provided the original work is properly cited.

\begin{abstract}
The search for suitable organic growing media substitutes for pine bark based media combinations has been prompted by concerns over high costs and lack of availability to smallholder farmers coupled with increasing demand for soilless media in Zimbabwe. A trial was conducted for 12 weeks to investigate the suitability of tea tree compost-based substrates for tobacco seedling production as a substitute of the traditional pine bark growing media. The use of composted tea tree growing media in float trays significantly $(p<0.05)$ increases the bulk density of the media by $23-59 \%$ when compared with pine bark media. The cation exchange capacity of the native pine bark growing media was 14 to $95 \%$ lower than that for the composted tea tree media. The use of the composted tea as media for tobacco seedling nursery reduced seed germination by $10-37 \%$, seedling stem height by $4-34 \%$, and seedling stem girth by $6-175 \%$. While the nutrient holding and supplying potential of the growing media in seedling production is important for normal seedling growth, its effect on seedling growth vigor is less important than that exerted by the presence of suitable physical conditions in the media.
\end{abstract}

\section{Introduction}

Leaf tobacco is one of the major cash crops in Zimbabwe for export [1]. It has higher profit returns than major crops grown in the country such as cotton and maize. The crop contributes more than $50 \%$ of annual agricultural exports. Zimbabwe has become the fourth largest producer of leaf tobacco in the world and largest producer in Africa [2].

Conventional leaf tobacco production systems usually require seedling propagation in standard seedbeds $(1 \mathrm{~m} \times$ $30 \mathrm{~m}$ ). Before the soil is made up into seedbeds it should be treated with chemicals to kill the minute threadlike worms known as nematodes. These nematodes are parasites of tobacco roots and can cause severe reductions in the growth of tobacco plants [3]. This convectional system has, for the past forty years, been utilizing methyl bromide to control soil-borne diseases and pests. The chemical is mainly used as a preplant soil sterilant and disinfectant, which kills a broad spectrum of insect pests, weeds, and soil pathogens and a single treatment before planting controls nematodes, diseases, and weeds. In Zimbabwe, much of the methyl bromide is used to sterilize soils in tobacco and horticultural nurseries, as well as grain fumigation [4]. The detrimental effect of methyl bromide on the atmospheric ozone layer, which controls passage of harmful ultraviolet radiation from the sun, has raised environmental concerns on the continued use of this chemical as a biocide fumigant [5-7].

Thus, new cost effective, environmentally compatible strategies for control of nematodes and other soil-borne pests and pathogens were to be developed and tested in a relatively 
short time to avoid significant losses in tobacco crop productivity $[6,8]$. The most promising substitute to the conventional methyl bromide-based tobacco seedling production method is the floating tray system [9]. It is a hydroponics or flooded bench fertigation system in which trays are filled with artificial media and floated in a pond where nutrients are periodically added. Capillary action carries water to the seed, which resides on the surface of the media filling the tray cells $[4,10,11]$.

The use of tree bark as a growth medium was reviewed extensively by Pokorny [12]; Aaron [13]; Pudelski [14]; Bunt [15]; Miller and Jones [16]; and Gartner and Williams [17]. Pine bark has been the most widely used soilless growing media constituent for the production of tobacco seedlings in float bed and ebb-flood fertigation systems because of its suitable chemical and physical properties for propagating and growing plants [4].

Ideal growing media should have suitable physical and chemical properties [18]. A good growing medium must have enough weight to provide physical support [19]. For a given container type and growing medium, excessive bulk density is a measure of compaction. Bulk density and porosity are said to be inversely related; when bulk density increases, porosity decreases [20]. Artificial growing media are generally pestfree [21-23].

The water holding capacity of the growing media is of importance as it has a bearing on seed germination and watering frequency [24, 25]. Microspores in growing media are important for absorption of water and holding it against the pull of gravity $[19,26]$. According to Hartmann et al. [27], a good growing medium will have a high water-holding capacity and at the same time contain enough macrospores to allow excess water to drain away and prevent water logging. In pine bark based medium, only $50 \%$ of water is said to be available to plant while the other $50 \%$ is not [19]. In addition, growing media should have good aeration porosity, which is percentage of air filled macrospores that are left after drainage of excess water $[28,29]$.

The search for suitable substitutes for pine bark media combinations has been prompted by concern over high costs and skewed availability to smallholder tobacco farmers coupled with increasing demand for soilless growing media [3, 21]. The hips of tea tree oil (Melaleuca alternifolia L.) compost produced annually in Zimbabwe may be an alternative source of soilless growing media for production of tobacco seedlings as well as another source of revenue for the tea tree farmer. Melaleuca alternifolia is a small tree of about 7 metres with a bushy crown and whitish, papery bark. It is commonly known as narrow-leaved paper bark, narrow-leaved tea tree, or snow-in-summer in the myrtle family, Myrtaceae. The tree grows well along streams and wetlands. Its leaves are linear, $10-35 \mathrm{~mm}$ long and $1 \mathrm{~mm}$ wide. The leaves are rich in oil with the glands prominent. The leaves are used to produce antibacterial melaleuca oil [30].

Numerous experiments with combinations of pine bark and compost sourced from multiple organic wastes mixed at different proportions were conducted for various plant species $[9,31]$. The current study was conducted to investigate the suitability of tea compost-based substrates used as tobacco seedling growing media in comparison with the pine bark growing media. Accordingly, we report in this paper on an experiment led for 12 weeks in which five composted tea tree waste and sand media combinations and one pine bark media treatment were used to test their effect on selected biometric characteristics of tobacco seedlings.

\section{Materials and Methods}

2.1. Description of the Site. The experiment was carried out at Kushinga Phikelela National Farmer Training College $\left(18^{\circ} 11^{\prime} \mathrm{S} ; 31^{\circ} 30^{\prime} \mathrm{E} ; 1200 \mathrm{~m}\right.$ above sea level), in the municipality of Marondera, Zimbabwe. It is located $90 \mathrm{~km}$ south-east of Harare along the Harare-Mutare highway. The site is in agroecological region $2 \mathrm{~b}$ which receives annual rainfall ranging from 750 to $1000 \mathrm{~mm}$ (mean $875 \mathrm{~mm}$ per annum) with insignificant frost occurrence in the months of June and July. The annual temperature ranges from 15 to $20^{\circ} \mathrm{C}$ with insignificant frost occurrence in the months of June and July. Rainfall occurs during a single rainy season extending from November to April [32, 33].

2.2. Construction of Floating Bed for the Trial. The trial commenced with construction of a floating bed measuring $3.60 \mathrm{~m}$ long, $1.05 \mathrm{~m}$ wide, with a height of $25 \mathrm{~cm}$ and a wall thickness of 2-brick courses $(20 \mathrm{~cm})$. The size of the floating tray bed was determined by the number of replicate float trays in the experiment. The entire construction was lined with $250 \mu$ black plastic sheeting, which was at least $1.50 \mathrm{~m}$ wider and longer than inside dimensions of the floating bed to allow for the plastic to be laid over the top of the wall to hold the plastic in place. The floating bed was then filled with water to a depth of $12-15 \mathrm{~cm}$. This effectively flattened the plastic against the sides of the pond and any wrinkles were pulled straight during this final exercise. The depth of water in the flooded bench left a space for tray depth that is desired for a floating tray to be level with bed.

\subsection{Preparation and Analysis of the Growing Media Material} for the Trial. The sand media material was extracted from sandy loam soil collected from a field at the training college. The soil was extensively shaken to pass a $2 \mathrm{~mm}$ sieve. Since $93 \%$ of the sandy loam soil textural particles were sand, most of the sieved soil material was sand (Table 3) which eventually was used as a growing media component. The texture of the sieved soil material was determined using the sedimentation method as described by Bouyocous [34].

Samples of sieved soil were analyzed for organic carbon (C) [35] and total $\mathrm{N}$ using the Kjeidahl procedure [36]. Exchangeable $\mathrm{K}^{+}, \mathrm{Mg}^{2+}$, and $\mathrm{Ca}^{2+}$ cations were extracted from the soil using a $1 \mathrm{~N} \mathrm{NH}_{4} \mathrm{OAc}$ extracting solution at $\mathrm{pH}$ 7.0. The extracted solution was then analyzed by atomic absorption for the soil cations. Available phosphorus in the soil sample was determined by the method described by Olsen and Watanabe [37].

Three $25 \mathrm{~L}$ buckets of sieved sandy soil were subjected to acid treatment by adding oxalic and hydrochloric acids and allowed to stand for 7 days in order to dissolve traces of nutrients shown in Table 3. The treated soil was then 
thoroughly washed with distilled water in order to leach out solubilized nutrients from the sand media. The $\mathrm{pH}$ of sand media was maintained between 5.5 and 5.6 by adding either lime or citric acid. The sand media were then spread onto an open plastic-laid surface and sun dried for 5 days.

The tea tree compost material for the experiment was generated following procedures described in the British Standards Institution's Publicly Available Specification for Composted Materials (BAS PAS 100: 2011) and the Compost Quality Protocol of 2008 [38]. Three empty $90 \mathrm{~kg}$ polystyrene bags were filled with composted tea tree media from hips of mature compost for use in the media combinations with sand.

Pine bark is a by-product of the pine wood and paper industries in the Eastern Highlands of Zimbabwe. The bark is stripped off the pine logs in the sawmills by debarking machines and has to be hammer milled to pass an appropriate screen, before being used in growth media, either fresh or after composting. Composted pine bark growing media were compared with the various combinations of composted tea tree matter with sand as alternative growing media. The composted pine bark based tobacco seedling growing media are not only expensive but having skewed availability to the majority of smallholder resettled tobacco farmers in Zimbabwe.

2.4. Analyses of the Pine Bark and Composted Tea Tree Media. Ten randomly selected samples were collected from composted tea tree and pine bark material and thoroughly mixed in plastic buckets. Three replicate composite samples were taken for laboratory analysis at the ZimLab (Pvt.) Ltd. in Harare. The physical properties of the tea tree compost, pine bark, and the various combinations of the compost and sand were determined following procedures described by Gabriels et al. [39] (Table 2). A method for determination of the selected chemical properties of the tea tree compost and pine bark growing media described by Gabriels et al. [40] was used in the study (Table 4).

2.5. Experimental Design and Treatments. Tobacco seedling growing media combinations of sand and composted tea tree were compared with pine bark media in the trial. Media were mixed at percentage ratio indicated in Table 1 . The different media combinations were premoistened for 18 hours and left covered with black plastic sheeting. This was done to allow media components to wick water before packing in float trays.

Media were then mixed with water slowly on a flat working surface. A simple hand feeling test was done to ensure enough water had been added. A mix containing the correct amount of moisture holds its shape when squeezed into a ball for 2-3 seconds before beginning to fall apart. Each tray was hand filled with the prepared media compositions by applying the standard methods. The trays were lifted to a height of about $20 \mathrm{~cm}$ above a flat surface and dropped gently. This slightly compacted the media in the trays. This was repeated 2-3 times with the trays being refilled after each drop. Underpacking results in media falling out through the holes at the bottom of the cells whilst overpacking introduces problems with dibbling and spiral roots of tobacco seedlings.
TABLE 1: Growing media mixes combinations for the experimental treatments.

\begin{tabular}{lccc}
\hline \multirow{2}{*}{ Treatments } & \multicolumn{3}{c}{ Components, in percentages (\%) by volume } \\
& Composted tea tree & Sand & Pine bark \\
\hline 1 & 100 & - & - \\
2 & 80 & 20 & - \\
3 & 70 & 30 & - \\
4 & 60 & 40 & - \\
5 & 50 & 50 & - \\
6 (control) & - & - & 100 \\
\hline
\end{tabular}

The trays were then dibbled using a dibble board and sown with pelleted KRK26 tobacco seed cultivar for each replicate. Each cell was then pressed at the centre to create depressions (dibbles) $1 \mathrm{~cm}$ deep. Sowing was done on the same day. All trays were floated in water bed on the same day. The trays were covered by seed bed cover sheet in order to provide favorable germination and emergence environment. The trays were floated following a randomized order in each block noting the water level of the floating bed. Each treatment was replicated three times in the floating bed.

2.6. Management of the Field Experiment. All treatments were subjected to the recommended basal application of hydrofert with NPK of $20: 10: 20$ at rates of $150 \mathrm{mg} \mathrm{L}^{-1}$ of water split into tree applications of 25,50 , and $75 \mathrm{mg} \mathrm{L}^{-1}$ at 7,21 , and 35 days after sowing, respectively. Top dressing by ammonium nitrate $(34.5 \% \mathrm{~N})$ to pond water was done at 42 days after sowing using a rate of $100 \mathrm{mg} \mathrm{N} \mathrm{L}^{-1}$ of water.

Tobacco seedlings were clipped by cutting off leaf tips to ensure uniformity and allow seedlings that lagged in growth and development to catch up with others. Clipping commenced at $5-7 \mathrm{~cm}$ height up to transplantable age. The standard procedures on tobacco seedling disease and pest control were employed.

Covering the float bed every night when the temperatures were low and uncovering during the day provided favorable temperatures in the range of $25-30^{\circ} \mathrm{C}$. Thermometers were used to monitor temperature changes in the seedbed.

2.7. Data Collection. Dry cells and fall-outs in the floating cells were counted and recorded 7 days after sowing (DAS). Germination and spiral root counts were undertaken between 14 and 35 DAS at weekly intervals for each replicate. Ten cells from 100 in the float tray centre were selected randomly for the germination and spiral root assessment. In this study, spiral rooting is taken as a condition when aerial roots develop as a result of a failure to grow downwards. A representative sample of 50 seedlings from the centre cells of each floating tray for a replicate was collected at the end of the experiment at 77 DAS for stem height and girth measurements using a graduated ruler and veneer calipers, respectively. The stem girth was measured at the middle of plant height for each seedling, which is between root crown and apical meristem. Ten plantlets per floating tray were 
TABLE 2: Media combinations and selected physical properties.

\begin{tabular}{|c|c|c|c|c|c|c|c|}
\hline \multirow{2}{*}{ Treatments } & \multicolumn{7}{|c|}{ Physical characteristics } \\
\hline & $\mathrm{TV}, \mathrm{cm}^{3}$ & $\mathrm{BD}, \mathrm{gcm}^{-3}$ & $\mathrm{PD}, \mathrm{gcm}^{-3}$ & Total porosity, $\%$ & Aeration porosity, $\%$ & WHC, $\mathrm{gcm}^{-3}$ & $\mathrm{EC}, \mathrm{mScm}^{-1}$ \\
\hline T6 100\% pine bark (control) & 290 & 0.48 & 1.86 & 71.3 & 38.7 & 43.2 & 0.96 \\
\hline $\mathrm{T} 1$ 100\% composited tea tree & 290 & 0.62 & 3.91 & 68.1 & 33.2 & 34.1 & 0.98 \\
\hline T2 80\% composited tea tree & 290 & 0.78 & 3.10 & 63.2 & 31.0 & 33.5 & 0.95 \\
\hline T3 70\% composited tea tree & 290 & 0.84 & 2.80 & 61.5 & 29.1 & 29.7 & 0.94 \\
\hline T4 60\% composited tea tree & 290 & 1.11 & 2.51 & 59.8 & 27.3 & 26.3 & 0.97 \\
\hline T5 50\% composited tea tree & 290 & 1.18 & 2.21 & 55.1 & 26.2 & 21.3 & 0.96 \\
\hline Fpr & NS & $<0.05$ & $<0.05$ & $<0.05$ & $<0.05$ & $<0.05$ & NS \\
\hline LSD & - & 0.04 & 0.22 & 1.5 & 0.7 & 3.4 & - \\
\hline CV\% & - & 4.6 & 8.1 & 5.3 & 3.8 & 4.8 & - \\
\hline
\end{tabular}

T1-T6: treatments, TV: total volume, BD: bulk density, PD: particle density, and NS: not significant.

TABLE 3: Nutrient content and $\mathrm{pH}$ of soil used in sand media preparation.

\begin{tabular}{lc}
\hline Mechanical analysis, $\mathrm{gkg}^{-1}$ soil & \\
Sand & 926 \\
Silt & 42 \\
Clay & 32 \\
Nutrient content, \% & \\
Organic C & 7.7 \\
Total N & 0.022 (interpreted as nil) \\
Exchangeable Ca & 0.109 \\
Exchangeable Mg & 0.014 \\
Exchangeable K & 0.018 \\
Soil pH & 6.1 \\
\hline
\end{tabular}

TABLE 4: Chemical properties of the composted tea tree and pine bark media.

\begin{tabular}{lcc}
\hline Measured variables & Tea tree & Pine bark \\
\hline $\mathrm{pH}$ & 6.4 & 4.2 \\
Total soluble salts $(\mathrm{ppm})$ & 3724.80 & - \\
Nitrate nitrogen $(\mathrm{ppm})$ & 5.62 & - \\
Phosphorous- $\mathrm{P}_{2} \mathrm{O}_{5}(\mathrm{ppm})$ & 207.16 & 17.9 \\
Calcium $(\%$ of CEC) & 20.73 & 17.5 \\
Potassium (\% of CEC) & 4.20 & 176 \\
Magnesium $(\%$ of CEC) & 10.78 & 5.80 \\
Sodium (\% of CEC) & 0.28 & - \\
Copper (\% of CEC) & 1.75 & 0.43 \\
Zinc (\% of CEC) & 73.05 & 3.3 \\
Iron (\% of CEC) & 46.8 & - \\
Manganese (\% of CEC) & 17.3 & 10.1 \\
Total exch. bases $(\%$ of CEC) & 35.99 & 8.8 \\
pH & 4.2 & 4.5 \\
\hline
\end{tabular}

selected randomly from 100 cells at the centre of trays for leaf counting at 77 DAS.

2.8. Statistical Analysis. Treatment effects on measured variables were analyzed using two-way ANOVA [41]. Differences between treatment means were judged significant at $p \leq 0.05$ as determined by Fisher's protected least significant difference test. Data on measured variables were log-transformed to normalize the distributions before the statistical analysis. Statistical significance of the differences between measured variables for the composted tea tree and pine bark media was established by performing $t$-test for unpaired samples using the GenStat package.

\section{Results}

3.1. Selected Physical Characteristics of the Growing Media Components. Blending components growth medium for tobacco seedling production yields physical properties that are intermediate between characteristics of the components. The physical properties of media greatly influence optimal management protocols. The physical properties of the different media combinations significantly $(p<0.05)$ influenced the performance and suitability of composted tea tree and pine bark substrates for growing tobacco seedlings in floating trays.

Results shown in Table 2 indicate that the use of composted tea tree growing media in float trays significantly $(p<0.05)$ increased bulk density of the media by $23-$ $59 \%$ when compared with that in the pine bark media. The bulk densities of the composted tea tree media combinations increased by an average of $0.14 \mathrm{gcm}^{-3}$ as the content of sand in the media increased. Particle density in the composted tea tree and sand media combinations increased consistently with increasing content of tea tree component at an average of $0.43 \mathrm{gcm}^{-3}$. As expected, the composted media combinations porosity decreased as the media bulk density increased thereby depicting an inverse relationship between the two variables. The water holding capacities the tea tree/pine bark media combinations increased with increasing pore spaces in the media (Table 2). The electrical conductivity (which is a measure of the salinity or total salt level of an aqueous solution) for various treatments in the study did not display significant differences $(p>0.05$, Table 2$)$.

3.2. Selected Chemical Characteristics of the Growing Media Components. Table 3 shows the nutrient contents of the sand media component used in the current study. Admixtures of 
composted tea tree material with sand had a varied content of sand ranging from 20 to $50 \%$. The concentrations of exchangeable $\mathrm{K}^{+}, \mathrm{Mg}^{2+}$, and $\mathrm{Ca}^{2+}$ in the soil from which the sand material was extracted were generally low (0.014$0.109 \%)$. Results of the soil analyses have shown that the concentration of $\mathrm{N}$ was comparatively negligible. The soil $\mathrm{pH}$, which is a major determinant of nutrient mobility in soils, was nearly neutral at 7.7 .

Table 4 shows some of the properties of the two organic growing media in float trays under the current comparative analyses. Media particle surface charges, which are responsible for the cation adsorption capacities, have a major effect on the chemical reactions taking place in the rhizosphere of the tobacco seedling root systems in the float trays. Results shown in Table 4 indicate the $\mathrm{pH}$ of native pine bark is comparatively lower than that of the tea tree compost.

Except for $\mathrm{K}^{+}$adsorption, the cation exchange capacities of the native pine bark growing media were 14 to $95 \%$ lower when compared with the cation exchange capacities for the composted tea tree media (Table 4). As a consequence of this trend, the total exchangeable bases in the composted tea tree media were $308 \%$ higher when rated against the percentage concentration of total exchangeable bases in the native pine bark.

\subsection{Effect of Media Mixes on Tobacco Seedling Emergence.} Seedling emergence count, which was conducted between 14 and 35 DAS, responded significantly ( $p<0.05$, LSD $8.1 \%$ ) to the use of composted tea tree and sand media combinations when compared with seedling emergence in float trays filled with the pine bark (Figure 1). The use of the composted tea based alternative as media material for tobacco nursery was accompanied by generally lower seedling emergence when compared with the emergence counts in the float trays filled with the traditional pine bark media (control). The control float trays where there were $100 \%$ pine bark media gave the highest emergence percentage of tobacco seedlings of $89 \%$. The $100 \%$ pine bark media recorded seedling emergences of $10-37 \%$ above the scores recorded in the floating trays filled with composted tea plus sand media combinations.

Results have shown that the introduction of the sand component into the composted tea media systematically reduces tobacco seedling emergence by $0.5 \%$ for every percentage increase in the content of sand. The lowest seedling emergence was recorded in the $50 \%$ composted tea plus $50 \%$ sand media mixes. Lower seedling emergence count coincided with the highest content of the sand component in the media (Figure 1).

3.4. Effect of the Media Types on Tobacco Seedling Spiral Root Development. There were significant differences $(p<$ 0.05 , LSD 1.9\%) in the tobacco seedling spiral root development between float trays filled with media combinations of composted tea tree and those filled with pine bark media (Figure 2). Generally, the use of composted tea tree waste as growing media in tobacco seedling propagation significantly $(p<0.05)$ increases the development of spiral roots by $71-97 \%$ when compared with spiral root development in

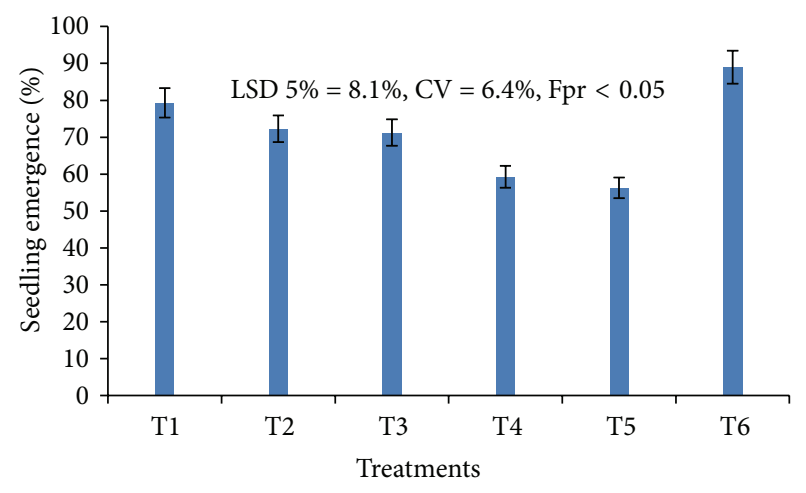

FIgURE 1: Seedling emergence. T1, Treatment 1; T2, Treatment 2; T3, Treatment 3; T4, Treatment 4; T5, Treatment 5; T6, Treatment 6.

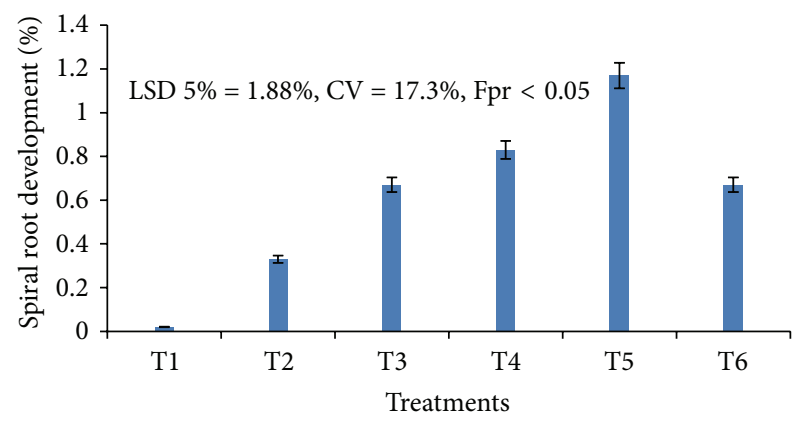

FIGURE 2: Spiral root development. T1, Treatment 1; T2, Treatment 2; T3, Treatment 3; T4, Treatment 4; T5, Treatment 5; T6, Treatment 6.

float trays filled with pine bark. Results have shown that increasing content of sand in the composted tea-based media combinations in float trays significantly increased $(p<0.05)$ the development of spiral roots in tobacco seedlings by $33-$ 98\% (Figure 2).

The absence of sand component in the composted tea material (Treatment 1 ) was accompanied by the lowest development of spiral roots in tobacco seedlings of $0.02 \%$. The highest development of spiral roots was recorded in the float trays with the highest content of sand in the composted tea media ( $50 \%$ composted tea $+50 \%$ sand in Treatment 5 ) when compared with that in the float trays filled with pine bark. Generally, every percentage increase in the content of sand in composted tea media introduced 0.02 percentage points increase in development of spiral roots in tobacco nursery. A combination in the nursery media of $70 \%$ composted tea and $30 \%$ sand recorded similar spiral root development as that recorded in float trays filled with $100 \%$ pine bark (control).

3.5. Effect of Media Type on Seedling Height. Study results show that there were comparatively detectable treatment separation signatures in tobacco seedling stem height $(p<$ 0.05 , LSD $5 \% 1.73 \mathrm{~cm}$ ) between tobacco seedlings growing in the composted tea tree waste media and those growing in the pine bark media (Figure 3). Mean seedling height varied between $13.5 \mathrm{~cm}$ (100\% pine bark) and $8.9 \mathrm{~cm}(50 \%$ composted tea and $50 \%$ sand). Seedling stem height in float 


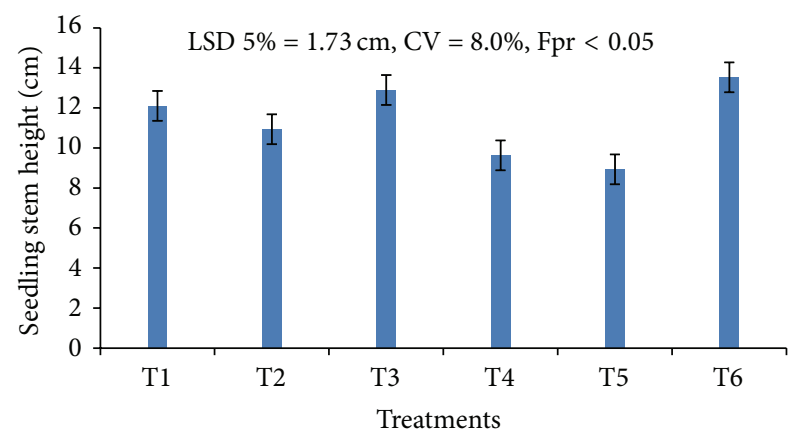

FIgURE 3: Seedling stems height. T1, Treatment 1; T2, Treatment 2; T3, Treatment 3; T4, Treatment 4; T5, Treatment 5; T6, Treatment 6.

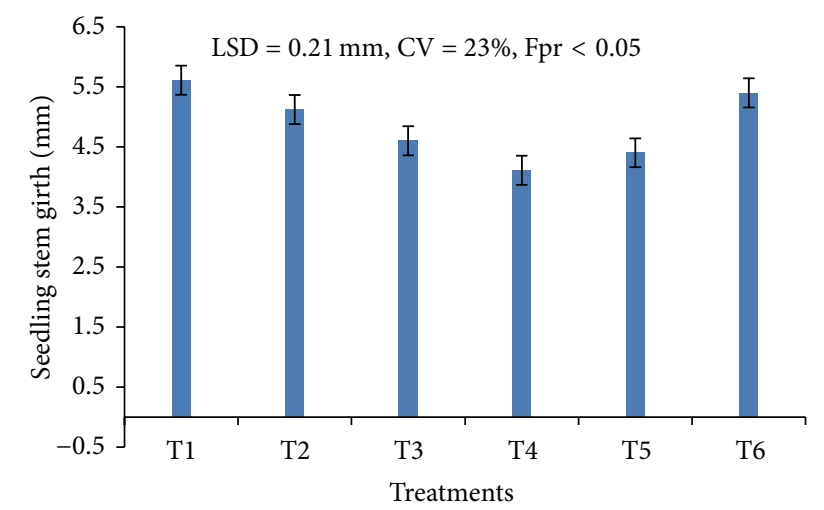

FIgUre 4: Seedling stem girth. T1, Treatment 1; T2, Treatment 2; T3, Treatment 3; T4, Treatment 4; T5, Treatment 5; T6, Treatment 6.

trays carrying composted tea tree/sand media combinations was $4-34 \%$ shorter than the stem height attained by tobacco seedlings that were propagated in the $100 \%$ pine bark growing media (control). The proposed alternative growing media for the tobacco nursery supported shorter stems when compared with the traditional pine bark based growing media. Results have shown that seedling stem height systematically became shorter with increasing content of sand in the composted tea tree based growing media (Figure 3).

3.6. Effect of Media Mixes on Stem Girth. There were significant $(p<0.05$, LSD 5\% $0.21 \mathrm{~mm})$ differences in the tobacco seedling stem girth between float trays filled with the composted tea tree + sand and stem girths of seedlings growing in float trays carrying pine bark media. The use of the traditional growing pine bark media for tobacco seedling propagation (100\% pine bark) scored thicker tobacco seedling stems by $4-$ $288 \%$ when compared with the use of the alternative growing media based on composted tea tree material. The thickest stems of tobacco seedlings observed in the $100 \%$ composted tea growing media float trays $(5.61 \mathrm{~mm})$ were $0.28 \mathrm{~mm}$ thicker than the tobacco seedling stems growing in the $100 \%$ pine bark media (control) float trays (Figure 4).

Except for the float trays filled with 50\% composted tea tree waste and $50 \%$ sand, the widths of the tobacco seedling stems measured at 77 DAS consistently decreased with increasing content of sand in the composted tea tree based

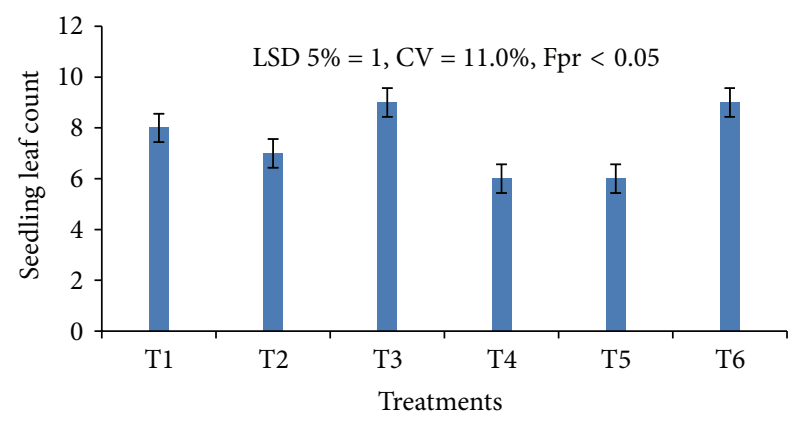

Figure 5: Seedling leaf count. T1, Treatment 1; T2, Treatment 2; T3, Treatment 3; T4, Treatment 4; T5, Treatment 5; T6, Treatment 6.

growing media (Figure 4). As the content of sand in the media combination increased from $20 \%$ to $50 \%$ the tobacco seedling girths decreased from $5.12 \mathrm{~mm}$ to $4.40 \mathrm{~mm}$. On average, the width of tobacco seedling stems decreased by $16 \%$ when the content of sand in the composted tea tree media was increased from 20 to $50 \%$.

3.7. Effect of Media Mixes on Tobacco Seedling Leaf Count. Leaf counts in float trays filled with composted tea tree matter were considerably different $(p<0.05)$ with those recorded in float trays filled with pine bark (Figure 5). The proposed alternative growing media based on composted tea tree did not perform better than the traditional pine bark based growing media on the number of leaf shoots recorded at 77 DAS. The use of the proposed alternative composted tea tree growing media in float trays considerably decreased tobacco seedling leaf count by $11-44 \%$ when compared with the leaf counts in float trays carrying pine bark media. However, comparatively similar leaf counts were recorded in tobacco seedlings growing in the $70 \%$ composted tea tree $+30 \%$ sand and $100 \%$ pine bark media. Similar leaf counts were recorded in tobacco seedlings growing in the $60 \%$ composted tea tree + $40 \%$ sand and $40 \%$ composted tea tree $+60 \%$ sand media combinations. Leaf counts in float trays performed at 77 DAS were significantly influenced $(p<0.05)$ by the combinations of composted tea tree and sand growing media. Except for $70 \%$ composted tea tree $+30 \%$ sand, the leaf count scores generally decreased with increasing content of sand in the composted tea tree based growing media.

3.8. Correlations between Measured Variables. Figures 6-9 show the regression analyses indicating the direct and the indirect effects of media combination bulk density and total porosity on tobacco seedling emergence and spiral rooting. The regression analysis has shown that the relationships between bulk density, total porosity of the growing media, tobacco seedling emergence, and spiral were significantly $(p<0.05)$ correlated with $R^{2}$ values ranging from 0.871 to 0.947. Higher values of the coefficients of determination $\left(R^{2}\right)$ of the relationships between growing media combination bulk density and seedling emergence $\left(R^{2}=0.947\right)$ and media total porosity and seedling emergence $\left(R^{2}=0.923\right)$ were recorded when compared with the $R^{2}$ values for the 


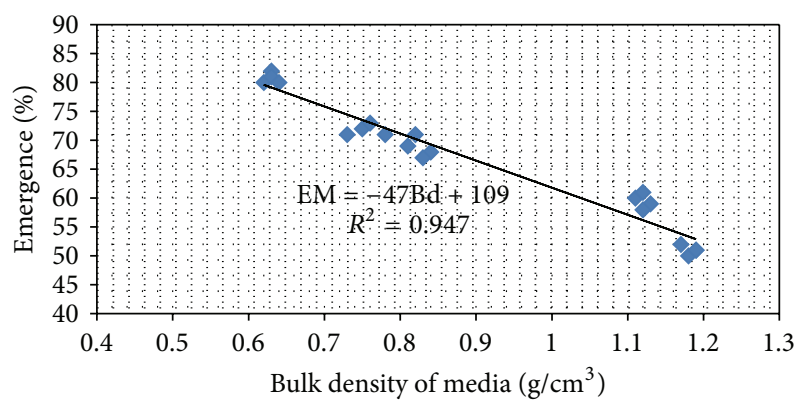

FIGURE 6: Regression analyses showing relationship between media bulk density and tobacco seedling emergence. EM, seedling emergence; $\mathrm{Bd}$, media bulk density.

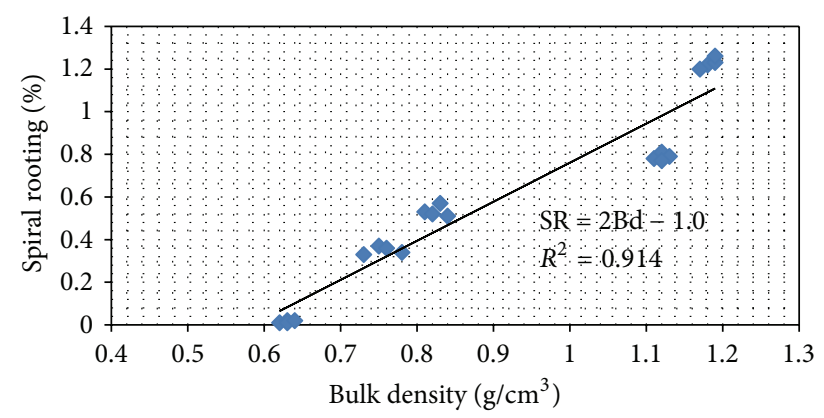

FIGURE 7: Regression analyses showing relationship between media bulk density and tobacco seedling spiral rooting. SR, seedling emergence; Bd, media bulk density.

relationship between media bulk density, total porosity, and seedling spiral rooting.

\section{Discussion}

4.1. Physical and Chemical Characteristics of the Growing Media Components. The suitability of growing media for tobacco seedling propagation is largely dependent on its capacity to support seedling emergence and growth vigor that eventually determine the seedling transplant survival and establishment in the field. The broad changes that occur in the bulk densities and porosity following various combinations of composted tea tree material with sand have been the subject of many studies internationally $[16,20,26,28]$. In a related study on pine bark container media, Pokorny [12] arrived at the conclusion that when media are composed of more than one ingredient, the physical characteristics of each ingredient contribute to the total bulk density of the medium. In the current study, the growing media are composed of more than one ingredient and the characteristics of each ingredient contribute to the total bulk density of the medium $[9,21,24]$. The media components that differ significantly in particle size have higher bulk densities as a mix [3]. Although particle size distribution was not described in this study, it is suspected that the composted tea tree media components differed considerably in particle size which introduced higher bulk densities in composted tea tree media when compared with the pine bark growing medium $[9,22]$. The sand which

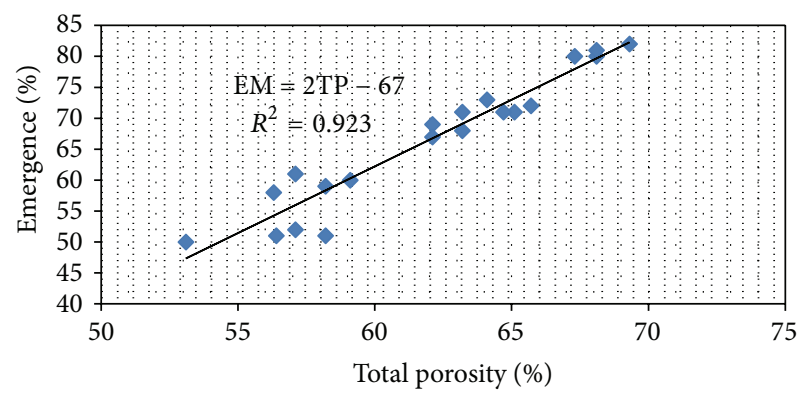

FIGURE 8: Regression analyses showing relationship between media total porosity and tobacco seedling emergence. EM, seedling emergence; TP, media total porosity.

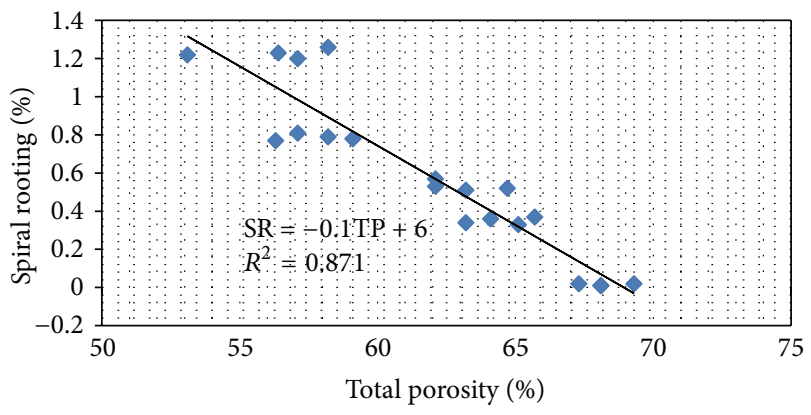

FIGURE 9: Regression analyses showing relationship between media total porosity and tobacco seedling spiral rooting. SR, seedling emergence; TP, media total porosity.

was added as a component of the composted tea tree growing media has a potential to increase the bulk density of the media mix $[8,29]$. The greatest liability to increasing additions of sand in an effort to create a more solid anchorage for the growing tobacco seedlings in float trays is that porosity (and hence air space) may be reduced significantly, requiring careful irrigation management to avoid water-logging and anoxia of tobacco seedling roots. The bulk density of the media combinations of composted tea tree waste with sand was higher when compared with that recorded in the pine bark. As a result, the total porosity, water holding capacity, and air-filled porosity of composted tea tree growing media were generally lower than those recorded in the pine bark medium.

It is generally recommended that sand can be added as a media component in Zimbabwe for tobacco seedling production in flooded benches in the outdoor system in order to increase the bulk densities for prevention of container instability in windy conditions that can blow over the float trays [18]. This can be achieved by the inclusion of heavy mineral constituents, such as sand, in the mix [24]. On the other hand, high-intensity tobacco seedling production systems in float trays which are in flooded benches may be exposed to oxygen deficiency if hydraulic conductivity and air-filled porosity are not high in growing media with high bulk densities [29]. In the current study, such a scenario is likely to prevail in the composted tea tree media. In a related study on the evaluation of different organic growing media for growth and flowering of pentuna, Dubey et al. 
[8] reported that for high-intensity greenhouse crops, which are frequently irrigated, there is a possibility of exposure to oxygen deficiency if hydraulic conductivity and air-filled porosity are not high due to high bulk densities. When the air filled porosity ranges from 10 to $15 \%$, media ambience is often water logged and algae that compete with plant for nutrients can grow in the float tray cells $[18,29]$. An air filled porosity of 15 to $20 \%$ is ideal for the float tray use in tobacco seedling production. On the other hand, an air filled porosity of more than $30 \%$ may be desirable for seed germination and ready to foster plant growth, especially in the floating tray system where water is always available [10].

The high bulk densities scored by the composted tea tree and sand media when compared with the traditional pine bark media can pose challenges associated with anoxic ambience in the float trays $[9,22]$. When the media mix is dense with an air content of less than $10 \%$ there is a possibility of poor seedling root aeration which causes stunted growth [28]. Another consideration in the comparison of the composted tea tree and sand media combination against the traditional pine bark media is that the mixing and transportation of the high bulk density components in the proposed alternative media are difficult, labor intensive, and expensive.

As expected, the media combinations porosity decreased as the media bulk density increased thereby depicting an inverse relationship between the two variables. The water holding capacities of the tea tree/pine bark media combinations increased with increasing pore spaces in the media. In related studies on physical characteristics of various growing media Bunt [15]; Bilderback et al. [11]; Spiers [28]; and Carlile et al. [19] reported increased moisture retention and available water content coupled with reduced air space and total porosity when pine bark is blended with sand to produce media. In the current study, addition of sand to composted tea tree material consistently increased the bulk densities and correspondingly reduced total porosity and water holding capacity (Table 2).

In the current study, the two types of organic growing media displayed cation adsorption properties shown in Table 4. It is suspected that the surface charges responsible for the cation adsorption characteristics in this study were created during the gradual decomposition of hemicellulose, cellulose, and to a lesser extent the lignin components in the composting of the tea tree waste [21,25]. These changes were accompanied by an increase in cation exchange capacity (CEC) and humic acid content in lingo-protein polymerization processes $[8,17]$. Nutrient retention sites are associated with the organic fractions of composted organic waste which become positively charged when the $\mathrm{OH}^{-}$radical in alkaline and slightly alkaline conditions link up with positively charged $\mathrm{H}^{+}$component on the exposed edges of the organic fractions of the media (R-COOH, R-H, R-OH, etc.) to form water [12, 19,27]. Essentially, the process involving the removal of $\mathrm{H}^{+}$ions or deprotonation (the $\mathrm{H}^{+}$ions are nothing more than just a proton in the nucleus) is responsible for the creation of negative charges on the exposed edges of the organic media molecules $[17,26]$ and will hold positively charged ions whose concentrations in the media are shown in Table 4 .
Results of the current study have demonstrated that the cation exchange capacities of the native pine bark growing media were 14 to $95 \%$ lower when compared with the cation exchange capacities for the composted tea tree media (Table 4). This implies that the capacity of the exposed edges of the organic molecules of composted tea tree to generate negativity for cation adsorption is comparably higher when compared with that of the traditional pine bark. In this respect, the composted tea tree media as an alternative to the more expensive and less available pine bark have a greater potential to adsorb and hold cationic nutrients and therefore reduce their susceptibility to loss through leaching into the flooded bench ambience. As a consequent of this, the total exchangeable bases in the composted tea tree media were $308 \%$ higher when rated against the percentage concentration of total exchangeable bases in the native pine bark. However, the fact that the organic fraction in the composted tea tree component of the media had a greater negativity as indicated by the higher concentration of the adsorbed cations (Table 4) implies that the composted tea tree media potentially exhibited a greater ability to repel negatively charged phosphate ions shown in Table $4\left(\mathrm{H}_{2} \mathrm{PO}_{4}{ }^{-}\right.$and $\left.\mathrm{HPO}_{4}{ }^{-2}\right)$ causing a higher possibility for them to be lost from the media by leaching into the flooded benches.

\subsection{Effect of Media Type on Selected Biometric Characteristics.} Research has been inadequate on the effect of the use of composted tea tree and sand media mix, cheaper and more available soilless media, on some selected biometric characteristics of tobacco seedlings, which are fundamental determinants of the field leaf yield and quality of tobacco. High content of available water and an adequate air supply have been considered as the most important physical characteristics required for container media in order to achieve optimal growth $[25,31]$. Study results show that there were distinct treatment signatures on germination and the selected biometric characteristics of tobacco seedlings in float trays $(p<0.05)$.

Generally, germination incorporates those events that commence with the uptake of water by the quiescent dry seed and terminate with the elongation of the embryonic axis $[20,23]$. Results of the current study have clearly indicated that the use of the composted tea based alternative as media material for tobacco nursery causes generally lower seed germination percentages when compared with the emergence counts in the float trays filled with the traditional pine bark media (control, Figure 1). It is noted that the bulk density, which determines the total porosity and hence water holding capacity of composted tea tree waste, is $23 \%$ higher in the composted tea tree when compared with the bulk density of the traditionally used pine bark (Table 2). Consequently, the water holding capacity of the pine bark growing media was considerably higher (43.2\%) than that of the composted tea tree material (34.0\%). The planted tobacco seeds absorb water, activating the biochemical mechanisms required for germination and growth [17, 21]. After absorbing enough water, the embryo bursts the seed's outer shell and the small growing tobacco seedling emerges. By virtue of its superior ability to hold more water in the media ambience, the 
traditional pine bark supplied the water for seed germination in quantities beyond the requirements of the tobacco seed to register a greater percentage of seed germination when compared with the composted tea tree waste growing media.

Because of its role in stand establishment, seed germination remains a key determinant of modern leaf tobacco production in Zimbabwe and elsewhere. The inferior ability of the composted tea tree growing media to support higher germination percentages than the one supported by the traditional pine bark clearly points to the fact that the composted tea tree matter as an alternative to the pine bark requires a more improved particle size combination that can enhance the water holding capacity of the media.

Results of the study have consistently indicated that the content of sand in the composted tea tree growing media reduces tobacco seedling emergence. This is attributed to the fact that the content of sand in the composted float tray growing media consistently increased the bulk densities of the composite media (Table 2). As a consequence, the total porosities correspondingly declined together with the water holding capacities of the media. This implies that the capacities of the growing media to supply the water in adequate quantities capable of triggering tobacco seed germination declined with increasing content of the sand component in the composite tea tree growing media. However, the introduction of the sand component in the float tray growing media is important for the stability of the float trays in flooded benches.

Spiral roots, which are better known in scientific circles as negative geotropism or negative gravitropism, can be a significant problem in some tobacco transplant greenhouses $[9,24,26]$. A spiral-root seedling occurs when the central cylinder of the root cap of the germinating seedling, which contain starch crystals that respond to gravity, is damaged and grows aerially or on top of the media and not down into the media [23]. Often the seedling develops a secondary root that grows into the media and the seedling may survive [24]. However, in most cases the seedling's growth is delayed and usually it will not result in a useable transplant [3]. Results of the current study have indicated that increased content in the sand media is accompanied with higher spiral root development in the tobacco seedlings (Figure 2). Generally, composted tea tree media, which is the proposed substitute for the less available and more expensive pine bark based growing media, scored lower tobacco seedling spiral development. In the current study, the bulk densities of the composted tea tree growing media increased with the increasing contribution of the sand component to the growing media. It is suspected that as the fragile tobacco seed germinates inside a pellet filled with high density matter such as sand, damage to the expanding root tip could prevent a normal geotropic response, which we know as spiral root.

Generally, the tobacco seedlings propagated in float trays filled with the traditional pine bark media (control) recorded superior biometric measurements when compared with those scored by the seedlings grown in proposed alternative composted tea tree waste and sand media combinations (Figures 3-5). After subjecting the pine bark and all composted tea tree waste treatments to the recommended basal application of hydrofert $(20: 10: 20)$ and ammonium nitrate fertilizer $(34.4 \% \mathrm{~N})$ as top dressing at $42 \mathrm{DAS}$, seedlings growing in the pine bark media had taller and thicker stems with a higher leaf count when rated against those recorded in the float trays filled with the composted tea tree waste based media. This trend in the superior ability of the pine bark media to support improved growth of tobacco seedlings was in direct contrast to the fact that the cation exchange capacities of the native pine bark were 14 to $95 \%$ lower than the cation exchange capacities for the composted tea tree media. In this context, float trays filled with composted tea tree waste based media combinations should have supported tobacco seedlings with a higher vegetative growth vigor than those growing in the pine bark media by virtue of its higher nutrient supply potential from the improved cation exchange capacity. This was however not the case in the current study. It is noted in this study that despite the inferior potential of the pine bark media to display better nutrient holding and supplying potential when compared with the composted tea tree, pine bark had better physical properties in terms of the bulk densities than those recorded in the composted tea tree waste. The composted tea tree waste generated a higher volume of voids occupied by water and air by virtue of its smaller densities when compared with that of the composted tea tree matter. It is suggested in this study that while the nutrient holding and supplying potential of the growing media in seedling production is important for normal seedling growth, its influence on seedling growth vigor is less important than that exerted by the presence of suitable physical conditions in the media.

The implications of the current study results concur with the conclusions arrived at by Landis et al. [20] who reported that good growing media should exhibit inherently low fertility characteristic. In similar studies, Majdi et al. [21] and Mahamud and Manisah [29] reported that plants at seedling stage grow better under low fertilization. In addition, beneficial microorganisms, such as mycorrhizal fungi, sometimes require low fertility to become established on plant roots [22].

In this study, it is noted that the demand for adequate supply of nutrients from the media ambience by the tobacco seedlings may still be low because of the smaller seedling biomasses and smaller rooting systems. This translated to a more pronounced influence of the physical properties of the organic growing media and a corresponding lower influence of the chemical properties of the media on the biometric variables of the tobacco seedling plantlets in float trays.

4.3. Regression Analysis between Measured Variables. The influence of media bulk density and total porosity on variability found in tobacco seedling germination and spiral rooting in the float trays was considerably strong as shown by the $R^{2}$ values of the relationships between the selected measured variables (Figures 6-9). In related studies on tobacco seedling production in float beds, Masaka et al. [24] and Gungor and Yildirim [25] reported that the bulk density of the growing media and its derivative, the total porosity, is of fundamental importance in float bed tobacco seedling production as it has 
a bearing on seed germination and watering frequency. The microspores in growing media act as conduits for absorption of water and holding it against the pull of gravity $[19,26]$. Hartmann et al. [27] reported that a good growing medium has water-holding capacity and enough macrospores to allow excess water to drain away and prevent water logging. In the current study the comparatively similar values of the coefficients of determination $\left(R^{2}\right)$ of the relationships between bulk density and tobacco seedling germination $\left(R^{2}=0.947\right.$; Figure 6), bulk density, and spiral rooting $\left(R^{2}=0.914\right.$; Figure 7) imply that the influence of the bulk density of a growing media on tobacco seedling germination and spiral rooting is comparatively the same. The same trend was recorded for the relationships between total porosity, germination, and spiral rooting. The bulk density and total porosity are thought to contribute immensely to the tobacco seed germination and spiral rooting although the latter has been suggested to play a bigger role in the growth and development of the tobacco seedlings.

\section{Conclusion}

Composted tea tree based growing media mixes with sand fail to replace the traditional pine bark based media mixes when the two media mixes are compared on the basis of provisions of desirable air porosities. However, the composted tea tree media as an alternative to pine bark have a greater capacity to adsorb cationic nutrients in aqueous conditions and therefore reduce the loss of vital plant nutrients by leaching. However, the use of the composted tea based alternative as media material for tobacco nursery causes generally lower seed germination percentages when compared with the emergence counts in the float trays filled with the traditional pine bark media. In addition to that, tobacco seedlings grown in float trays filled with the traditional pine bark media recorded superior biometric measurements when compared with those recorded by the seedlings grown in proposed alternative composted tea tree waste and sand media combinations. It can be concluded that while the nutrient holding and supplying potential of the growing media in seedling production is important for normal seedling growth, its effect on seedling growth vigor is less important than that exerted by the presence of suitable physical conditions in the media.

\section{Conflict of Interests}

The authors declare that there is no conflict of interests regarding the publication of this paper.

\section{Acknowledgments}

This research was conducted under the Midlands State University. The authors acknowledge the contributions by Tippet family and Glensila Tobacco Estate staff for provision of the composted tea tree substrate and related information on the product. Their sincere gratitude goes to the ZimLab for full analysis of the substrate at affordable costs.

\section{References}

[1] FAO, Global Watch Report, Rome, Italy, 2001.

[2] I. P. S. Ahlawat, Tobacco, Division of Agronomy, Indian Agricultural Research Institute, New Delhi, India, 2004.

[3] U. Mazarura, A Guide to Use of Floating Tray System for Tobacco Seedling Production in TRB, Kutsaga Publications, Harare, Zimbabwe, 2004.

[4] K. Flower, G. Thomas, D. Cole, J. Way, and C. Cottrell, Alternatives to the Use of Methyl Bromide in Tobacco Production in Zimbabwe: A Preliminary Guide to the Use of Alternative Soil Fumigants and the Float System, UNIDO, 2002.

[5] J. W. Noling and J. O. Becker, "The challenge of research and extension to define and implement alternatives to methyl bromide," Journal of Nematology, vol. 26, no. 4, pp. 573-586, 1994.

[6] M. S. Majewski and P. D. Capel, Pesticides in the Atmosphere, Ann Arbor Press, Chelsea, Mich, USA, 1995.

[7] U.S. Environmental Protection Agency, Integrated Risk Information System (IRIS) on Bromomethane, National Center for Environmental Assessment, Office of Research and Development, Washington, DC, USA, 1999.

[8] R. K. Dubey, Simrat-Singh, S. S. Kukal, and H. S. Kalsi, "Evaluation of different organic growing media for growth and flowering of petunia," Communications in Soil Science and Plant Analysis, vol. 44, no. 12, pp. 1777-1785, 2013.

[9] M. Raviv, "The future of composts as ingredients of growing media," Acta Horticulturae, vol. 891, pp. 19-32, 2011.

[10] M. J. Van Schoor, I. E. Smith, and C. L. Davis, "Preparation and utilization of pine bark as a growing medium of plaints," Pietermaritzburg, South Africa, 1990.

[11] T. E. Bilderback, W. C. Fonteno, and D. R. Johnson, "Physical properties of media composed of peanut hulls, pine bark and peat moss and their effect on azalea growth," Journal of the American Society for Horticultural Science, vol. 107, pp. 522-525, 1999.

[12] F. A. Pokorny, "Pine bark container media: an overview," in Proceedings of the International Plant Propagators' Society Combined Proceedings, vol. 29, pp. 484-495, 1979.

[13] J. R. Aaron, “Conifer bark: its properties and uses," Forest Record 110, Forestry Commission, Bristol, UK, 1982.

[14] T. Pudelski, "Woodwaste composts as growing media for vegetables under protection," Acta Horticulturae, vol. 172, pp. 6774, 1985.

[15] A. C. Bunt, Media and Mixes for Container-Grown Plants, Unwin Hayman, London, UK, 1988.

[16] J. H. Miller and N. Jones, "Organic and compost-based growing media for tree seedling nurseries," World Bank Technical Paper 264, Washington, DC, USA, 1995.

[17] J. B. Gartner and D. J. Williams, "Horticultural uses for bark: a review of current research," Horticulture Technology, vol. 15, no. 1, pp. 52-57, 2005.

[18] M. Asaduzzaman, M. Saifullah, A. K. M. Salim Reza Mollick, M. Mokter Hossain, G. M. A. Halim, and T. Asao, "Influence of soilless culture substrate on improvement of yield and produce quality of horticultural crops," in Soilless Culture-Use of Substrates for the Production of Quality Horticultural Crops, M. Asaduzzaman, Ed., chapter 10, pp. 400-413, InTech, Rijeka, Croatia, 2015.

[19] W. R. Carlile, C. Cattivello, and P. Zaccheo, "Organic growing media: constituents and properties," Vadose Zone Journal, vol. 14, no. 6, pp. 11539-1663, 2015. 
[20] T. D. Landis, R. W. Tinus, S. E. McDonald, and J. P. Barnett, The Container Tree Nursery Manual: Volume 2, Containers and Growing Media, Agriculture Handbook no. 674, Department of Agriculture, Forest Service, Washington, DC, USA, 2010.

[21] Y. Majdi, M. Ahmadizadeh, and R. Ebrahimi, "Effect of different substrates on growth indices and yield of green peppers at hydroponic cultivate," Current Research Journal of Biological Sciences, vol. 4, no. 4, pp. 496-499, 2012.

[22] K. Kowalczyk, J. Gajc-Wolska, and M. Marcinkowska, "The influence of growing medium and harvest time on the biological value of cherry fruit and standard tomato cultivars," Vegetable Crops Research Bulletin, vol. 74, no. 1, pp. 51-59, 2011.

[23] S. M. Singer, A. M. M. El-Tanahy, U. A. El-Behairy, and E. H. Abu El-Samad, "Growth and productivity of cantaloupe plants grown under different soilless culture systems," Journal of Applied Sciences Research, vol. 9, no. 8, pp. 5294-5302, 2013.

[24] J. Masaka, R. Musundire, and C. Koga, "A comparative study of pine bark substrate alternatives in tobacco (Nicotina tabacum) float seedling production systems," International Journal of Agricultural Research, vol. 2, no. 1, pp. 11-21, 2007.

[25] F. Gungor and E. Yildirim, "Effect of different growing media on quality, growth and yield of pepper (Capsicum annuum L.) under greenhouse conditions," Pakistan Journal of Botany, vol. 45, no. 5, pp. 1605-1608, 2013.

[26] B. De Lucia, G. Cristiano, L. Vecchietti, E. Rea, and G. Russo, "Nursery growing media: agronomic and environmental quality assessment of sewage sludge-based compost," Applied and Environmental Soil Science, vol. 2013, Article ID 565139, 10 pages, 2013.

[27] H. T. Hartmann, D. E. Kesters, F. T. Davies, and R. L. Geneve, Hartmann and Kester's Plant Propagation: Principles and Practices, Prentice Hall, New York, NY, USA, 8th edition, 2009.

[28] J. Spiers, Physical and Chemical Properties of a Good Soil Less Medium, Academic Press, London, UK, 2005.

[29] S. Mahamud and M. D. Manisah, "Preliminary studies on sago waste as growing medium for tomato," Acta Horticulturae, vol. 742, pp. 163-168, 2007.

[30] K. A. Hammer, C. F. Carson, T. V. Riley, and J. B. Nielsen, "A review of the toxicity of Melaleuca alternifolia (tea tree) oil," Food and Chemical Toxicology, vol. 44, no. 5, pp. 616-625, 2006.

[31] J. Nurzyński, "Yield and quality of greenhouse tomato fruit grown in rape straw substrates," Acta Scientiarum Polonorum, Hortorum Cultus, vol. 12, no. 1, pp. 3-11, 2013.

[32] V. Vincent and R. G. Thomas, An Agricultural Survey of Southern Rhodesia, Part I: Agro-Ecological Survey, Government Printers, Salisbury, Zimbabwe, 1960.

[33] R. Mugandani, M. Wuta, A. Makarau, and B. Chipindu, "Reclassification of agroecological regions of Zimbabwe in conformity with climate variability and change," African Crop Science Journal, vol. 20, pp. 361-369, 2012.

[34] G. J. Bouyocous, "Hydrometer method improved for making particle size analysis of soils," Agronony Journal, vol. 27, pp. 738741, 1965.

[35] D. W. Nelson and L. E. Sommers, Total C, Organic C and Organic Matter, vol. 9, part 2 of Agronomy Series, ASA, Madison, Wis, USA, 1982.

[36] J. M. Bremner and C. S. Mulvaney, "Nitrogen-total," in Methods of Soil Analysis, Agronomy Series no. 9, Part 2, pp. 595-622, Soil Science Society of America (SSSA), Madison, Wis, USA, 1982.

[37] R. S. Olsen and F. S. Watanabe, "A method to determine available phosphorus," American Society of Agronomy, vol. 21, no. 2, pp. 144-149, 1956.
[38] Wrap, Compost Production for Growing Media-A Good Practice Guide, Wrap, London, UK, 2011.

[39] R. Gabriels, W. Keirsbulck, and H. Engels, A Rapid Method for the Determination of Physical Properties of Growing Media, International Society for Horticultural Science, 1993.

[40] R. Gabriels, W. Keirsbulck, and H. Engels, A Rapid Method for the Determination of Chemical Properties of Growing Media, International Society for Horticultural Science, 1995.

[41] GenStat, GenStat for Windows, Introduction to GenStat. VSN International, Wilkinson House, London, UK, 7th edition, 2003. 


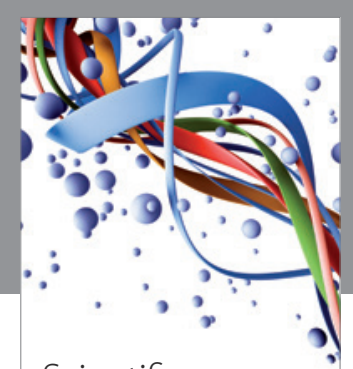

Scientifica
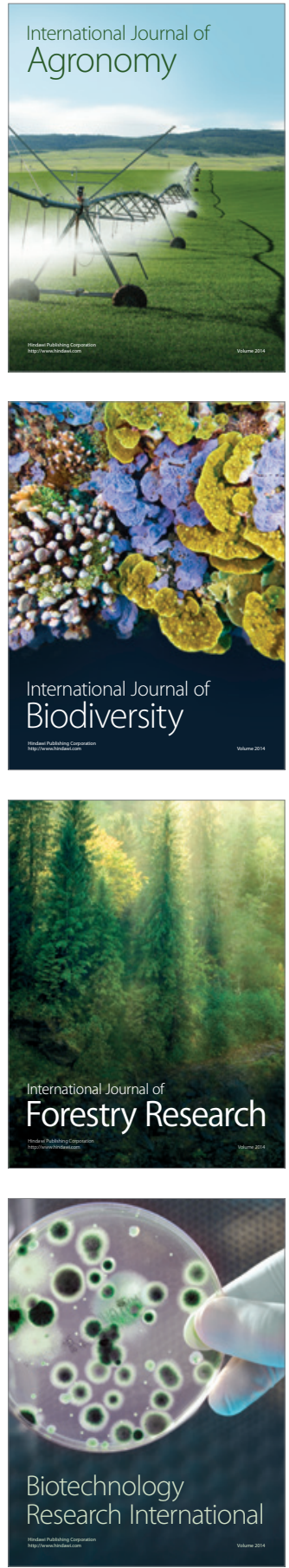
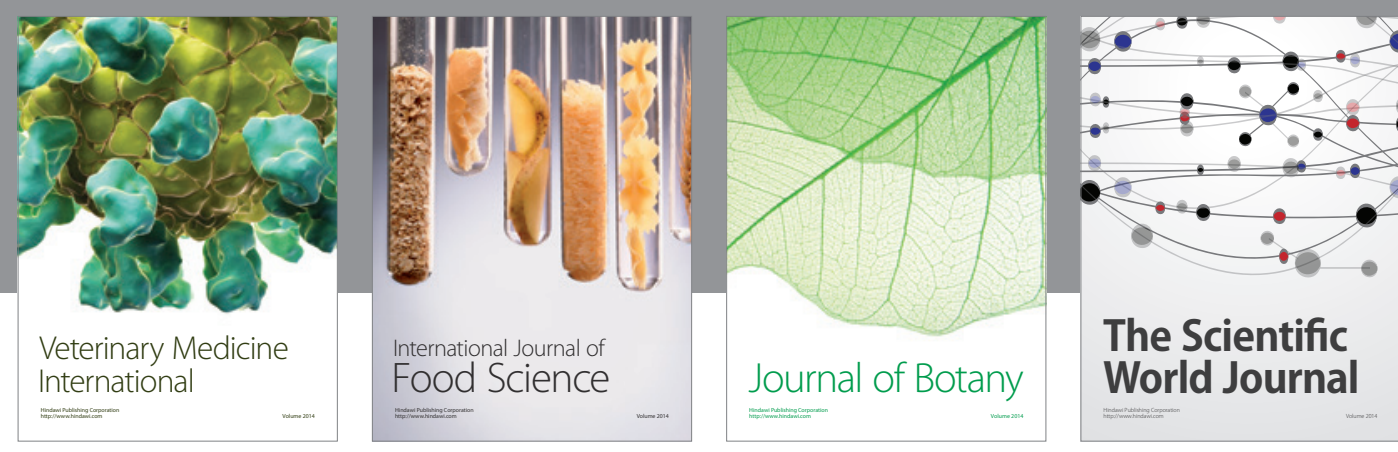

The Scientific

\section{World Journal}

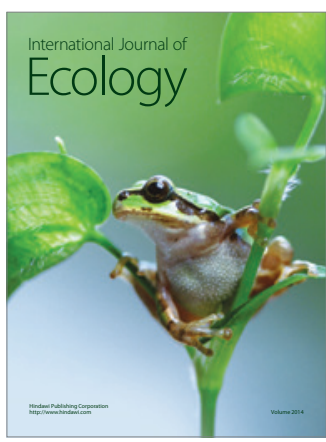

\section{Hindawi}

Submit your manuscripts at

http://www.hindawi.com
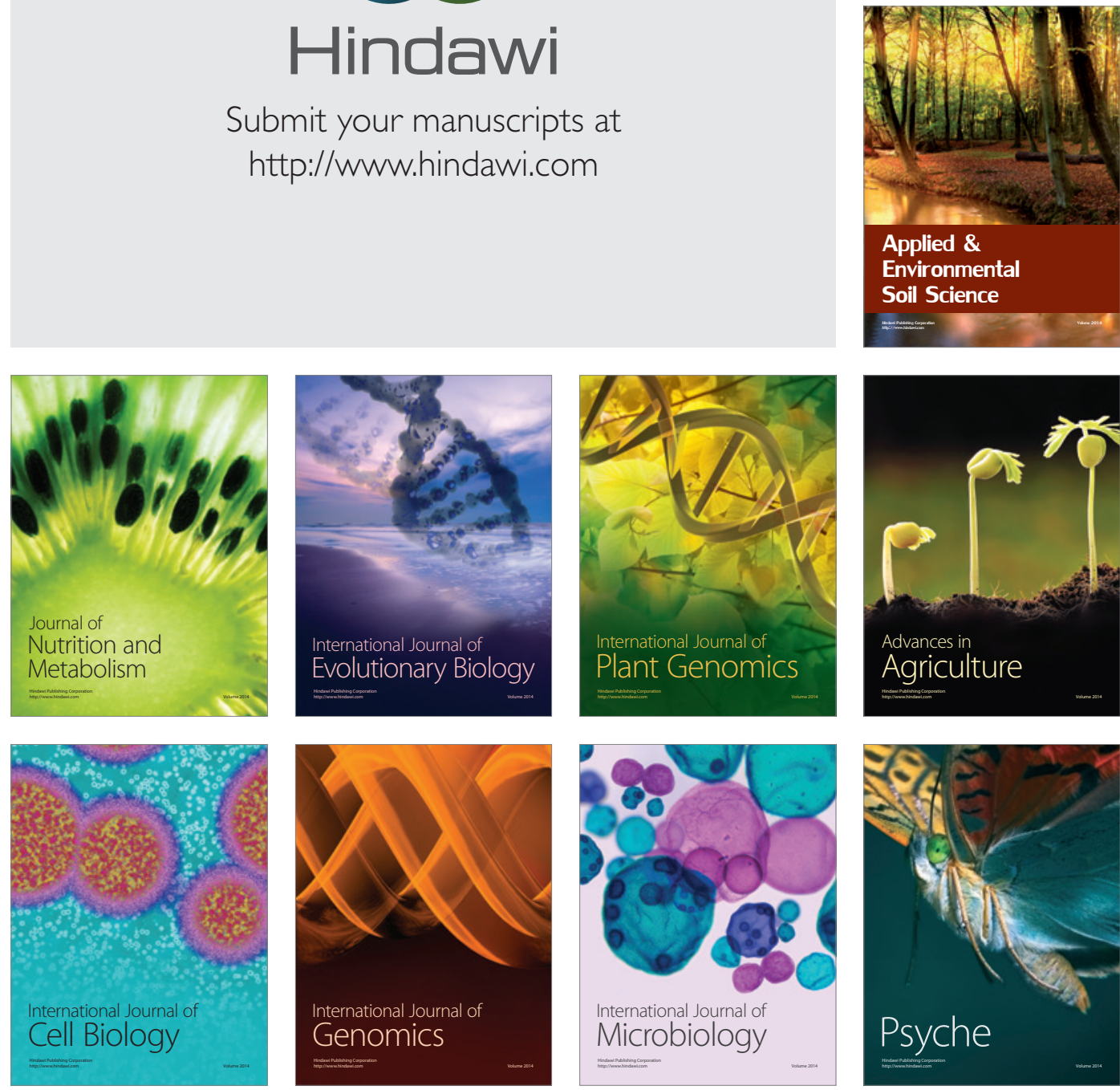
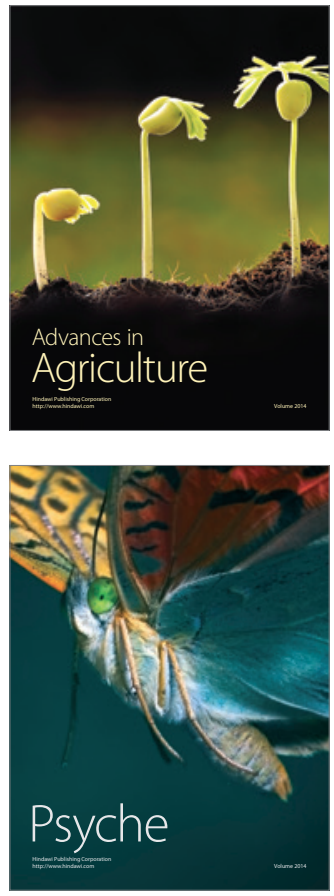